\title{
Effects of E-recruitment and internet on recruitment process: An Empirical study on Multinational companies of Bangladesh
}

\author{
Piana Monsur Mindia, Md. Kazimul Hoque \\ School of Business and Economics \\ United International University Bangladesh \\ School of Business and Economics \\ United International University Bangladesh
}

\begin{abstract}
Recruitment is a function of human resource management by which an organization can attract the potential candidates and select the most appropriate employees for the organization. Now-a-days the people are extensively adaptive to the technology and that's why e-recruitment has become a popular practice followed by the organization for hiring employees. This is an exploratory research with the aim of identifying how e-recruitment and internet is influencing the overall recruitment process of an organization in context of Multinational companies of Bangladesh. In this study, multinational organizations of Bangladesh have been taken as population according to their participation in erecruitment activities. The sample was drawn from the renowned companies and data were collected from various levels of respondents in context of the job seekers. Statistical analysis has been used to prove that there is a significant statistical analysis of how e-recruitment is practiced and the relationship between erecruitment and overall recruitment process. It also concluded that there is a moderate relationship between these two variables and the job seekers feel convenient to search potential jobs for their prosperous career. So it is recommended that the organization should continue to use e-recruitment and online sources for hiring candidates so that they can match with the global business world.
\end{abstract}

Keywords: Recruitment, E-recruitment, Multinational companies.

\section{Introduction}

The advancement of technology plays an important role in organizations functioning and overall development of Bangladesh. As our country is a developing nation and it has set its mission to be digitalized in every arena, the organization also has started to use technology in their activities. Before the technological advancement, organization used various sources to recruit employees. Those sources are newspaper advertisement, campus recruiting, different job agencies and so on. Those sources are also recognized as traditional recruitment sources. But now along with those sources many other sources have been added to this list because of the technological development. Various job related websites, recruitment via internet, Email, social media etc. are the sources which added with traditional recruitment which is known as erecruitment. E-recruitment is a mode for selecting one of the companies' human resources through technological mean. According to technological acceptance model, the uses of online sources for job searching have been impressively increased. It is considered to be effective because it saves time, effort and moreover it can ensure that suitable person is hired for a particular position. So the main purpose of our study is to identify about how e-recruitment and internet is influencing the recruitment process of an organization.

\section{Literature Review}

Kaur discussed that, the process of finding and hiring the best-qualified candidate (from within or outside of an organization) for a job opening is a timely and cost effective manner. The recruitment process includes analyzing the requirements of a job, attracting employees to that job, screening and selecting applicants, 
hiring, and integrating the new employee to the organization. (Kaur, 2015) Essentially, the process involves seeking and attracting a pool of qualified applicants using various feasible recruitment methods.

\section{Recruitment Methods}

The conventional recruitment methods used by organizations consist of contacting friends or employee referrals, engaging executive search, using newspapers classified ads, and others. (Tong \& Sivanand, 2005)

According to Sills, when broken down, the term "E-recruitment" is comprised of two parts. The "E" stands for "electronic" and "recruitment". Often, E-recruitment is known as online recruiting, social recruiting or Internet recruiting, however, this thesis will refer to E-recruitment for simplicity. To add to the previously introduced definition of recruitment, E-recruitment can only be described as the process of any personnel advertising or attracting, selection and application processing via the Internet, for external candidates, or Intranet, for internal candidates. (Sills, 2014)

Laxmi identified that, the prime focus of using e-recruitment is to get a large pool of applications. It assures the organization to get a competent person for the job position from the large pool of applicants. There are two methods of recruitment followed by the organizations.

\section{Traditional Methods}

- Using sources that are not technology supported, like advertisement, flyers, Spokespersons, to draw as many applicants as possible to contact the organization. (Searching Candidates)

- Using paper-based test for applicants to create a manageable applicants pool. (Screening)

- Contacting the sorted applicants by phones and having face to face conversations. (Interview)

- Making the phone call, setting up the meeting and shaking hands. (Placement)

\section{Modern Methods}

- Using the organizations Reputation product image, online technology and other methods to draw as many as possible to the organizations websites. (Searching Candidates)

- Employing sophisticated, standardized online tests to screen candidates, and to winnow the applicant pool to a manageable number (Screening).

- Using automated hiring management system to contact the most desirable candidate very quickly, before they are snapped by another company. (Online Interview)

- Making the phone call, setting up the meeting and shaking hands (Placement Order by email)

In early-1990s, with the advancement of internet technology, many have witnessed the transformation of the conventional recruitment methods to online recruitment. (Joyce, 2002)

E-recruitment is a new technological mean for selecting one of the companies' most crucial resources, i.e. human resource. This technological innovation improves the process of recruiting knowledge sources by using the Internet. It allows businesses to make cost savings, update job offers and status at any time, to shorten the recruitment cycle time, to identify and select the best knowledge potential out of a wider range of candidates and gives the company an opportunity to improve its image and profile. (Anand J, 2016)

According to (Anand J, 2016) the fundamentals of e-recruitment are as follows:

- Tracking: It is helpful in tracking the status of candidate with respect to the jobs applied by him/her.

- Employer's Website: Provides details of job opportunities and data collection for same.

- Job portals: Like CareerAge, Indeed, Monster, Naukri, timesjobs, etc these carry job advertisements from employers and agencies. 
- Online Testing: Evaluation of candidates over internet based on various job profiles to judge them on various factors.

- Social networking: Sites like google +, twitter, facebook, linkedin, etc helps in building strong networking and finding career opportunities.

The companies cannot risk loosing qualified candidates due to bad organized workflows leading e.g. to late responses when interacting with applicants. But how can companies assure that they are able to attract large quantities of highly qualified candidates? (Malinowski, Keim, \& Weitzel, 2005) This question can be found in Tong \& Sivanand's research. According to it, Effective e-recruitment service providers often support jobseekers with comprehensive job information and some with career enhancement tools in the web sites, which they can conveniently assess for their career plan. (Tong \& Sivanand, 2005) The availability of internet connections, good speed and affordable broadband connections today's generation is spending a plenty of time on internet. And therefore, the recruiters are focusing on making social media a tool for posting job opportunities on popular websites in order to attract a large pool of candidates without any geographical restrictions. (Rana \& Singh, 2015)

(J \& S, 2016) discussed, the employer must learn to reach job seekers by creating profiles on Facebook, Linked In (social networking) along with using job portals for making recruitment more effective. Also they can advertise job vacancies with the numerous online recruitment agencies -to brace the talent hunt process.

\section{Research Methodology}

\section{Sources of Data Collection:}

Primary and secondary sources of data were gathered for the research. Primary source of data was collected through the use of questionnaires and survey interviews. The secondary sources of information were collected from past research work, books, journals, articles, internet search, etc.

\section{Methods for collecting Primary Data:}

In collecting data for the study, questionnaire and direct interview methods were employed. The questionnaire was used to ensure that only relevant questions were asked and also to ensure that the questions were properly structured.

\section{Data Collection Tool:}

The questionnaire was the only tool used to collect data. Likert type (close ended) questionnaire was employed to generate data. The importance of the use of close ended questions was to avoid delays in responding to the questionnaire, thus enabling the respondents who had busy schedules to respond quickly. Another reason for using close ended questions was that coding of close ended questions did not take much time as compared to open ended questions/ and also for testing hypothesis.

\section{Sampling:}

A sample of hundred (120) respondents were drawn from thirty (30) multinational companies located in our country. Convenience sampling technique has been used to derive data from different levels of employees. 
Table 1: Correlations

\begin{tabular}{|l|l|c|c|}
\hline \multicolumn{2}{|l|}{} & $\begin{array}{c}\text { Average of } \\
\text { traditional } \\
\text { recruitment }\end{array}$ & Average of E-recruitment \\
\hline $\begin{array}{l}\text { Average of traditional } \\
\text { recruitment }\end{array}$ & Pearson Correlation & 1 & $.590^{* *}$ \\
\cline { 2 - 4 } & Sig. (2-tailed) & - & .000 \\
\cline { 2 - 4 } & $\mathrm{N}$ & 110 & 110 \\
\hline $\begin{array}{l}\text { Average of E- } \\
\text { recruitment }\end{array}$ & Pearson Correlation & $.590^{* *}$ & 1 \\
\cline { 2 - 4 } & Sig. (2-tailed) & .000 & - \\
\cline { 2 - 4 } & $\mathrm{N}$ & 110 & 110 \\
\hline
\end{tabular}

Pearson correlation between Average of Traditional Recruitment and Average E-Recruitment is 0.590 and $\mathrm{P}-$ Value is 0.000 . This indicate that there is a moderate uphill (positive) relationship $(\mathrm{r}=0.590)$, and that the correlation coefficient is moderately different from zero $(\mathrm{P}<0.001)$.

This means that there is a moderate relationship between your two variables and as one variable increases in value, the second variable also increases in value. This means that changes in one variable are moderately correlated with changes in the second variable. For this reason, we can conclude that there is a moderate relationship between traditional recruitment system and e-recruitment system. However, we cannot make any other conclusions about this relationship, based on this number.

Table 2: Regression Coefficients

\begin{tabular}{|l|r|r|r|r|}
\hline Model & R & \multicolumn{1}{|l|}{ R Square } & Adjusted R Square & \multicolumn{2}{|c|}{ Std. Error of the Estimate } \\
\hline 1 & $.635^{\mathrm{a}}$ & .403 & .362 & .47788 \\
\hline
\end{tabular}

a. Predictors: (Constant), E-recruitment system

The value of Pearson correlation is .635 , which that there is a moderate degree of positive relationship between the two variables. The relationship is perfect. The e-recruitment system is reducing the usage of traditional recruitment system but still the traditional recruitment is using to some extent. Correlation can tell here just how much the e-recruitment is reducing the usage of traditional recruitment system.

Also this correlation technique works best with linear relationships: as one variable gets larger, the other gets larger (or smaller) in direct proportion. It does not work well with curvilinear relationships (in which the relationship does not follow a straight line). Above is an example of a linear relationship. They are related, and follow a straight line.

$\mathrm{R}$-squared is a statistical measure of how close the data are to the fitted regression line. It is also known as the coefficient of determination. $\mathrm{R}$ square represents the proportion of variability accounted for by the independent variable. Approximately $40.3 \%$ of the variability exists in this model which indicates that the model explains a substantial proportion of the variability of the response data around its mean. In general, the higher the R-squared, the better the model fits the data. 
Table 3: ANOVA

(The ANOVA Table shows the significance level at .000)

\begin{tabular}{|l|r|r|r|r|r|}
\hline Model & \multicolumn{1}{|c|}{ Sum of Squares } & \multicolumn{1}{|c|}{ df } & \multicolumn{1}{|c|}{ Mean Square } & \multicolumn{1}{c|}{ F } & Sig. \\
\hline Regression & 15.710 & 7 & 2.244 & 9.827 & .000 \\
\hline Residual & 23.294 & 102 & .228 & & \\
\hline Total & 39.003 & 109 & & & \\
\hline
\end{tabular}

a. Predictors: (Constant), E-recruitment system

b. Dependent Variable: Average of traditional recruitment

The hypothesis of the study was to ascertain that E-recruitment is reducing the practice of regular or traditional recruiting system. The view was further supported by the result of the Analysis of Variance (ANOVA) which yielded an $\mathrm{F}$ value of 9.827 , and $\mathrm{P}$ Value of 0.000 , significant at $0.000 \%$. Hence, this implies that the e-recruitment system is reducing the practices of regular or traditional recruiting system.

Conclusion \& Recommendations:

Recruitment process is very much crucial to every organization, because it's the people who can contribute strategically and make difference in the workplace. Today this process has become mostly digitalized because of advancement of technology. In the developed countries, e-recruitment has been used widely from a long period of time. But, as we are a developing country and many people do not possess technological expertise that's why this scenario is somehow different here. It could be concluded by the result of the analysis and interpretations that, although e-recruitment system is reducing the usage of traditional recruitment system but still the traditional recruitment is using to some extent in our context. In private organizations, banks and multinationals has been using e-recruitment but they also use the traditional process side by side. It is highly recommended that, the managers of these companies should continue to use these two methods at a time as long as the society becomes fully digitalized. Moreover, through the data collection process, it was also identified that, there are some loopholes present in the e-recruitment system, so these loopholes could be covered by using traditional methods. As an initial step of improvement, the management also should train the recruiters adequately for building an effective system for online recruitment system in these organizations. This study will further help the human resource managers to identify the relevant factors which may be taken into consideration in the process of overall recruitment.

\section{References}

1. Anand J, D. C. (2016). The Impact of E-Recruitment and challenges faced by HR Professionals. International Journal of Applied Research , 410-413.

2. Breaugh, J. a. (2000). Research on employee recruitment: so many studies, so. Journal of Management, 26(3), 405-34.

3. J, A., \& S, C. D. (2016). The Impact of E-Recruitment and challenges faced by HR Professionals. International Journal of Applied Research, 410-413.

4. Joyce, E. (2002). Bill Warren, E-recruiting Association. Retrieved July 26, 2002, from http://atnewyork.com/news/rticle.php/1433771

5. Kaur, P. (2015). E-recruitment: A conceptual study. International Journal of Applied Research, 7882.

6. Malinowski, J., Keim, T., \& Weitzel, T. (2005). Analyzing the Impact of IS Support on Recruitment Processes: An E-Recruitment Phase Model. PACIS 2005 Proceedings, 977-988.

7. Rana, T., \& Singh, N. (2015, May). SOCIAL MEDIA AS A TOOL FOR RECRUITMENT-A CRITICAL STUDY. International Journal of Science Technology and Management, 5(5), 203-210. 
8. S.L, L. (n.d.). E-RECRUITMENT: A BOOM TO THE ORGANIZATIONS IN THE COMPETITIVE WORLD. IOSR Journal of Business and Management, 25-28.

9. Sills, M. (2014). E-recruitment: A comparison with traditional recruitment and the influences of social media. Helsinki Metropolia University of Applied Sciences, European Management.

10. Tong, D. Y. (2008). A study of e-recruitment technology adoption in Malaysia. Industrial Management \& Data Systems, 109(2), 281-300.

11. Tong, D. Y., \& Sivanand, C. (2005). Service providers review: international and Malaysian. Employee Realtion, 27(1), 103-17. 